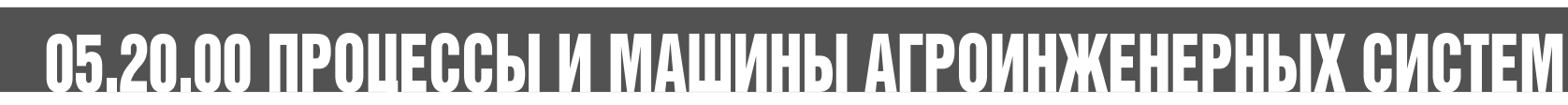

удК 621.372.413; 631.363

DOI 10.18286/1816-4501-2018-2-6-12

\section{АНАЛИЗ РАБОЧИХ КАМЕР, ОБЕСПЕЧИВАЮЩИХ ТЕРМООБРАБОТКУ И ГРАНУЛИРОВАНИЕ ОТХОДОВ СЕЛЬСКОХОЗЯЙСТВЕННОГО СЫРЬЯ}

Крайнов Юрий Евгеньевич ${ }^{1}$, преподаватель кафедры «Электрификация и автоматизация»

Михайлова Ольга Валентиновна ${ }^{1}$, доктор технических наук, профессор кафедры "Инфокоммуникационные технологии и системы связи»

Кириллов Николай Кириллович ${ }^{2}$, доктор ветеринарных наук, профессор

${ }^{1}$ ГБОУ ВО «Нижегородский инженерно-экономический университет»

606340, Нижегородская область, г. Княгинино, ул. Октябрьская, д. 22; e-mail: krainov24@mail.ru

${ }^{2}$ ФББОУ ВО «Чувашская государственная сельскохозяйственная академия» 428003, г Чебоксары, ул. К. Маркса, д. 29.

Ключевые слова: сверхвысокочастотный генератор, резонатор, гранулятор, матрица, отходы сырья, регрессионные модели, эфрфективные режимы.

Целью работы является разработка установки для гранулирования непищевых отходов животного и растительного происхождения с воздействием на них электромагнитного поля сверхвысокой частоты. $B$ задачи исследования входило: разработка микроволновой установки с объемным резонатором, обеспечивающим высокую напряженность электрического поля и непрерывность процесса гранулирования сырья; обоснование технологических параметров гранулятора с учетом основных критериев технологического процесса. В исследованиях базировались на теории диэлектрического нагрева и теории формования гранул из многокомпонентного сырья. Обработку результатов экспериментальных исследований выполняли с применением методов математической статистики и регрессионного анализа при использовании теории активного планирования многофакторного эксперимента. Разработана установка, обеспечивающая гранулирование сырья в непрерывном режиме при воздействии ЭМПСВЧ. Приведены ее описание и анализ конструкции объемного резонатора с учетом требований, предъявляемых к сверхвысокочастотным установкам, предназначенным для использования в фермерских хозяйствах. К основным требованиям относят возможность обеспечения: радиогерметичности СВЧ установки при непрерывном режиме работы; высокотемпературного формования гранул при высокой напряженности электрического поля; вариации производительности установки с маломощными магнетронами, охлаждаемыми воздухом. Анализ разработанной установки с иилиндрическим резонатором-матрицей показал, что эффрективны следующие режимы гранулирования комбинированной смеси: длина волны - 12,24 см; удельная мощность сверхвысокочастотного генератора - 1...1,4 Вm/2; продолжительность воздействия ЭМПСВЧ на сырье массой 0,8...1 кг в резонаторной камере - 10...12 с; плотность

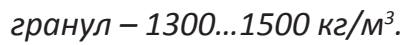

\section{Введение}

В настоящее время комбикормовая промышленность производит смеси различных компонентов в самых разных сочетаниях и пропорциях с использованием пресс-грануляторов высокой производительности [1, 2, 3, 4]. Но для фермерских хозяйств необходимо разрабатывать грануляторы производительностью всего
180...300 кг/ч, не использующие пар $[5,6]$. При этом требуется сохранить витаминный состав, улучшить микробиологические показатели и усвояемость гранул $[7,8,9]$. Известны грануляторы марки ГКМ, содержащие в рабочей камере матрицу и подвижные ролики, предназначенные для переработки зерновых отходов, отходов продуктовой сферы, шрота, жмыха в гранули- 
рованный комбикорм. При работе таких грануляторов не удается полностью сохранить витаминный состав, улучшить микробиологические показатели и усвояемость гранул. Поэтому разработка грануляторов со сверхвысокочастотным (СВЧ) энергоподводом [10, 11, 12, 13] актуальна.

Целью работы является разработка и обоснование параметров установки для гранулирования непищевых отходов животного и растительного происхождения с воздействием на них электромагнитного поля сверхвысокой частоты.

Задачи исследования:

1) разработать микроволновую установку с объемным резонатором, обеспечивающим высокую напряженность электрического поля и непрерывность процесса гранулирования сырья;

2) обосновать технологические параметры гранулятора с учетом основных критериев технологического процесса.

Объекты и методы исследований

В теоретических исследованиях применены теории диэлектрического нагрева и формования гранул. Экспериментальные исследования проводили в соответствии с разработанными частными методиками. Основные расчеты и обработку результатов экспериментальных исследований выполняли с применением методов математической статистики и регрессионно- го анализа в программах Statistic 12.0, Excel 16.0. Оценку технических характеристик установки проводили с помощью современных цифровых приборов и методик. Трехмерное моделирование конструкций СВЧ установок выполняли в программе Компас-3D V17.

\section{Результаты исследований}

Разработана установка, обеспечивающая гранулирование сырья в процессе воздействия электромагнитного поля сверхвысокой частоты (ЭМПСВЧ) в непрерывном режиме. Ниже приведено описание СВЧ установки, отвечающей требованиям, предъявляемым к ее использованию в фермерских хозяйствах, и проанализировано конструкционное исполнение объемного резонатора. К основным требованиям относят возможность обеспечения:

- радиогерметичности СВЧ установки при непрерывном режиме работы;

- высокотемпературного формования гранул при высокой напряженности электрического поля;

- вариации производительности установки с охлаждаемыми воздухом маломощными магнетронами.

Установка с цилиндрическим резонатором-матрицей для гранулирования измельченных отходов животного и растительного проис-
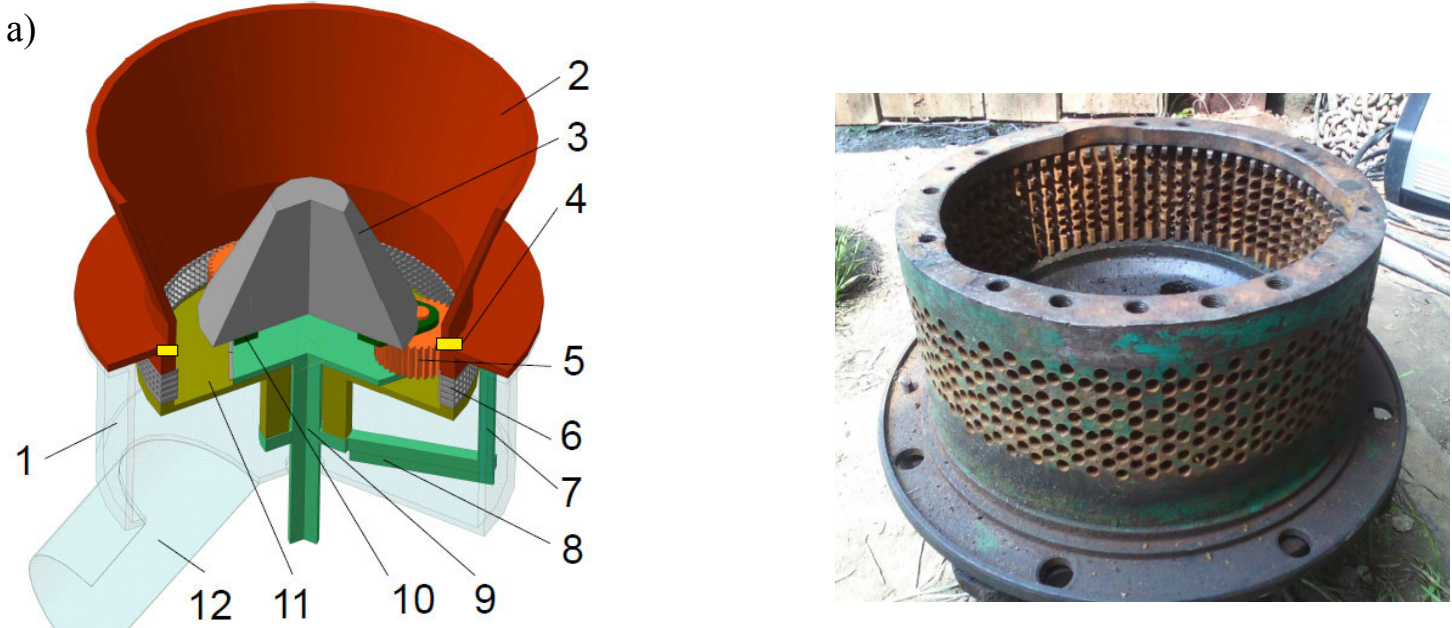

Рис. 1 - Установка с цилиндрическим резонатором-матрицей для гранулирования измельченных отходов животного и растительного происхождения в процессе диэлектрического нагрева:

a) 3-D модель: 1 - экранирующий корпус; 2 - загрузочная емкость из неферромагнитного материала; 3 - конусообразный экран; 4 - излучатели СВЧ генератора; 5 - прижимные диэлектрические ролики с ребристой поверхностью; 6- цилиндрическая матрица из неферромагнитного материала; 7-нож; 8-скребок; 9-вал электропривода; 10 - верхняя и нижняя диэлектрические плиты для крепления прижимных роликов; 11 - цилиндрический резонатор; 12 - выгрузной патрубок; б) общий вид цилиндрической матрицы 
Таблица 1

Технические характеристики микроволновой установки с цилиндрической матрицей

\begin{tabular}{|l|c|}
\hline \multicolumn{1}{|c|}{ Показатель } & $\begin{array}{c}\text { Значение } \\
\text { показателя }\end{array}$ \\
\hline Максимальная производительность, кг/ч & 350 \\
\hline Потребляемая мощность СВЧ генераторов, кВт & 3,6 \\
\hline Суммарная мощность электродвигателей, кВт & 7,5 \\
\hline Частота вращения матрицы, мин ${ }^{-1}$ & 140 \\
\hline Диаметр, мм & \\
- вальцов & 80 \\
- мешалки & 382 \\
\hline Количество, шт. & \\
- вальцов & 3 \\
- обламывающих ножей & 1 \\
\hline Диаметр радиальных отверстий в матрице, мм & 8 \\
\hline Габаритные размеры, мм & $1050 \times 525 \times 760$ \\
\hline Масса, кг & 220 \\
\hline
\end{tabular}

хождения с их диэлектрическим нагревом (рис. 1) состоит из цилиндрического экранирующего корпуса 1 с выгрузным патрубком 12, внутри которого соосно расположена рабочая камера в виде стационарно расположенного цилиндрического резонатора 11. Внутри резонатора установлены диэлектрические плиты 10, между которыми прикреплены прижимные диэлектрические ролики 5 с ребристой поверхностью. Ролики 5 установлены с плотным прилеганием к внутренней поверхности цилиндрической матрицы 6. Матрица 6 - съемная и вставлена в боковую стенку резонатора 11 так, что является его составной частью. Нижняя диэлектрическая плита 10, установленная в резонаторе соосно, расположена на вале 9 электропривода. На вале также смонтирован узел, который содержит вертикально расположенный с наружной стороны образующей резонатора нож 7 и скребок 8, установленный горизонтально над нижним основанием экранирующего корпуса. Экранирующий корпус состыкован с загрузочной емкостью 2, находящейся над ним и выполненной в виде воронки из неферромагнитного материала, внутри которой соосно расположен конусообразный экран 3. Основание конусообразного экрана 3 и нижнее основание загрузочной емкости расположены так, что между ними имеется кольцевое пространство толщиной менее, чем четверть длины волны. С боковой стороны цилиндрического резонатора по периметру установлены со сдвигом на 120 градусов излучатели 4 от СВЧ генераторов. Диэлектрические ролики прижаты к цилиндрической матрице 6 винтом, позволяющим регулировать расположение осей прижимных роликов. Цилиндрическая матрица может быть съемной, с разным диаметром отверстий для разного вида сырья. Диаметр и высота цилиндрического резонатора согласованы с длиной волны. Максимальные размеры резонатора не превышают 3...5 длин волны.

Технологический процесс гранулирования и обеззараживания сырья происходит следую-

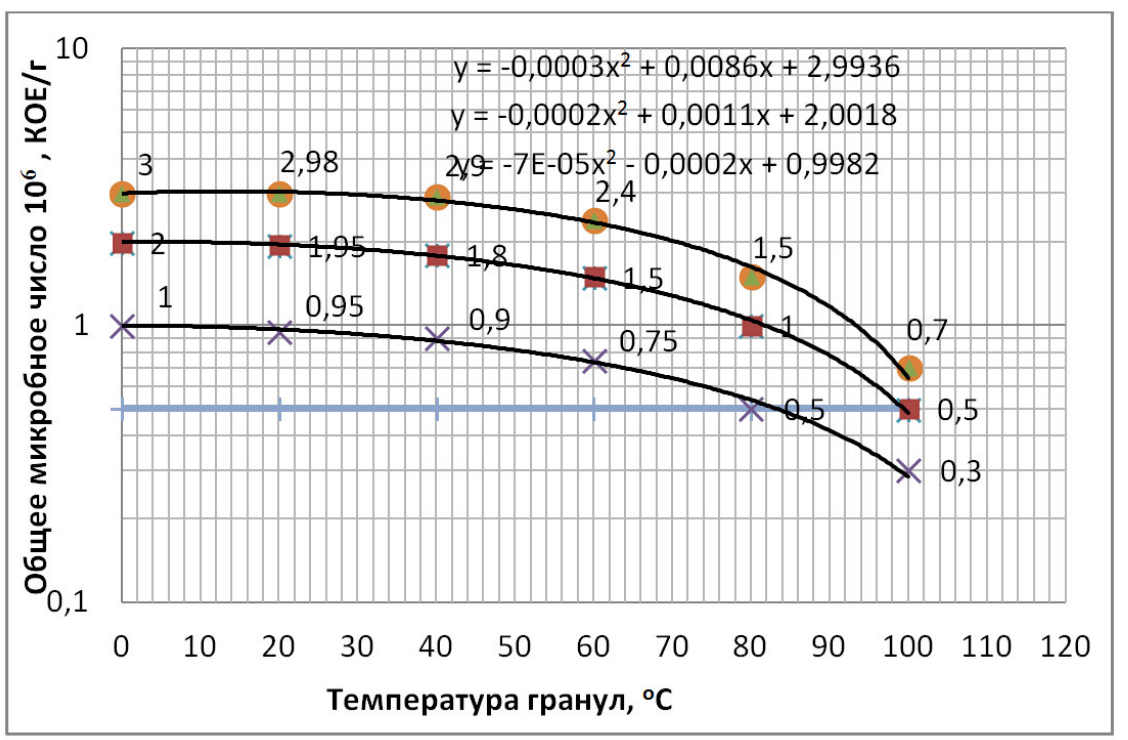

Рис. 2 - Изменения общего микробного числа в гранулах в зависимости от температуры нагрева при разной исходной обсемененности: 1 - 3 млн КОE/2; 2 - 2 млн KOE/2; 3 - 1 млн KOE/2 щим образом. Предварительно перемешивают многокомпонентное сырье, включающее отходы зерна (содержание зерна - до 30 \%) и непищевые отходы животного происхождения в определенной концентрации, так, чтобы влажность смеси не превышала 20 \% [8]. Включают электропривод диэлектрических прижимных роликов. Засыпают сырье в загрузочную емкость 2 и включают СВЧ генераторы. Сырье через кольцевое пространство между загрузочной емкостью и коническим экраном 3 попадает в цилиндрический резонатор 11, куда направлены излучатели 4. В этом случае отраженные волны не нарушают работу соседних 
Таблица 2

Матрица активного планирования эксперимента типа $2^{3}$ для оптимизации технологических параметров гранулятора с СВЧ энергоподводом

\begin{tabular}{|c|c|c|c|c|c|c|c|}
\hline \multirow{3}{*}{$\begin{array}{l}\text { № } \\
\Pi / \Pi\end{array}$} & \multicolumn{7}{|c|}{ Варьируемые параметры } \\
\hline & \multicolumn{2}{|c|}{$\begin{array}{c}\text { Удельная мощность } \\
\text { генератора, Вт/г }\end{array}$} & \multicolumn{2}{|c|}{$\begin{array}{c}\text { Частота вращения, } \\
\text { мин }^{-1}\end{array}$} & \multicolumn{2}{|c|}{$\begin{array}{c}\text { Диаметр радиальных от- } \\
\text { верстий в матрице, мм }\end{array}$} & \multirow{2}{*}{$\begin{array}{c}\text { Продолжительность } \\
\text { воздействия ЭМПСВЧ, } \\
\text { t, с }\end{array}$} \\
\hline & $x_{1}$ & $P_{\mathrm{yA}}$ & $x_{2}$ & об/мин & $x_{3}$ & d, $M M$ & \\
\hline 1 & + & 2,0 & + & 160 & + & 8 & 7,5 \\
\hline 2 & + & 2,0 & - & 120 & - & 4 & 9,5 \\
\hline 3 & - & 0,8 & + & 160 & - & 4 & 19 \\
\hline 4 & - & 0,8 & - & 120 & + & 8 & 23 \\
\hline 5 & 0 & 1,4 & 0 & 140 & 0 & 6 & 12 \\
\hline 6 & - & 0,8 & 0 & 140 & 0 & 6 & 21 \\
\hline 7 & + & 2,0 & 0 & 140 & 0 & 6 & 8,5 \\
\hline 8 & 0 & 1,4 & - & 120 & 0 & 6 & 13,5 \\
\hline 9 & 0 & 1,4 & + & 160 & 0 & 6 & 11,5 \\
\hline 10 & 0 & 1,4 & 0 & 140 & - & 4 & 12 \\
\hline 11 & 0 & 1,4 & 0 & 140 & + & 8 & 12 \\
\hline
\end{tabular}

магнетронов. В электромагнитном СВЧ поле, образованном в цилиндрическом резонаторе, сырье нагревается и обеззараживается. В связи с тем, что боковая поверхность резонатора образована цилиндрической матрицей 6, с помощью вращающихся прижимных диэлектрических роликов 5 с ребристой поверхностью нагретое сырье выдавливается через отверстия матрицы в виде гранул. Гранулы срезаются вращающимся ножом 7, установленным параллельно образующей цилиндрического резонатора. Далее срезанные гранулы с помощью вращающегося скребка 8 выгружаются через патрубок 12. Технические характеристики установки приведены в табл. 1

Таким образом, гранулятор с цилиндрическим резонатором-матрицей для гранулирования отходов животного и растительного происхождений обладает высокой производительностью и имеет возможность смены матриц с разными диаметрами отверстий.

Зависимости общего микробного числа (ОМЧ) в гранулах от температуры их нагрева приведены на рис. 2. Исследования показывают, что степень снижения микробиологической обсемененности зависит не только от температуры, но и от исходного общего микробного числа сырья.

Для выявления рациональных режимов работы гранулятора с цилиндрической матрицей применяли методику планирования 3-факторного активного эксперимента типа $2^{3}$ (табл. 2).

В качестве основных факторов, влияющих на технологический процесс гранулирова- ния смеси, были выбраны: удельная мощность CВЧ генератора $\mathrm{P}_{\text {уд }}, \mathrm{BT} / г\left(\mathrm{x}_{1}\right)$; частота вращения матрицы $\mathrm{n}$, мин $^{-1}\left(\mathrm{x}_{2}\right)$; диаметр радиальных отверстий в матрице $\mathrm{d}\left(\mathrm{x}_{3}\right)$. Выбор интервалов изменения факторов обусловлен: технологическими условиями формования гранул из многокомпонентных отходов; конструкционными параметрами гранулятора с СВЧ энергоподводом; зоотехническими требованиями. Выбранные факторы были совместимы и не коррелированы между собой, а пределы их изменения принимались равными: $\left(\mathrm{x}_{1}\right) 0,8 \leq \mathrm{P}_{\mathrm{yд}} \leq 2 \mathrm{Bт} / \mathrm{r} ;\left(\mathrm{x}_{2}\right)$ $120 \leq \mathrm{n} \leq 160$ об/мин; $\left(\mathrm{x}_{3}\right) 4 \leq \mathrm{d} \leq 8$ мм.

Критериями оптимизации являются: $Y_{1}-$ температура гранул $\left(\mathrm{T},{ }^{\circ} \mathrm{C}\right) ; \mathrm{Y}_{2}$ - производительность гранулятора $(Q, k г / 4) ; Y_{3}$ - доза воздействия ЭМПСВч (D, Вт.ч/г); $Y_{4}$ - удельные энергетические затраты на технологический процесс гранулирования фуражной пшеницы, (W, кВт·ч) кг); $Y_{5}$ - микробиологическая обсемененность гранул (общее микробное число, ОМЧ, КОЕ/г).

С использованием программы «Statistic V12.0» построены поверхности отклика, их двумерные сечения в изолиниях (рис. 3) и получены соответствующие регрессионные модели процесса гранулирования фуражной пшеницы при диаметре радиальных отверстий в матрице $4 \mathrm{Mm}$.

Регрессионные модели в натуральных значениях факторов имеют вид: $0,46 \cdot x_{1} \cdot x_{2}$

$\mathrm{T}=2,5+69,08 \cdot x_{1}+0,3 \cdot \mathrm{x}_{2}+1,75 \cdot \mathrm{x}_{1}{ }^{2}+0,0009 \cdot \mathrm{x}_{2}{ }^{2}+$

$$
\begin{aligned}
& Q=17,08-45,61 \cdot x_{1}+1,82 \cdot x_{2}+8,14 \cdot x_{1}{ }^{2}+0,00043 \\
& \cdot x_{2}{ }^{2}+0,0,15 \cdot x_{1} \cdot x_{2}
\end{aligned}
$$




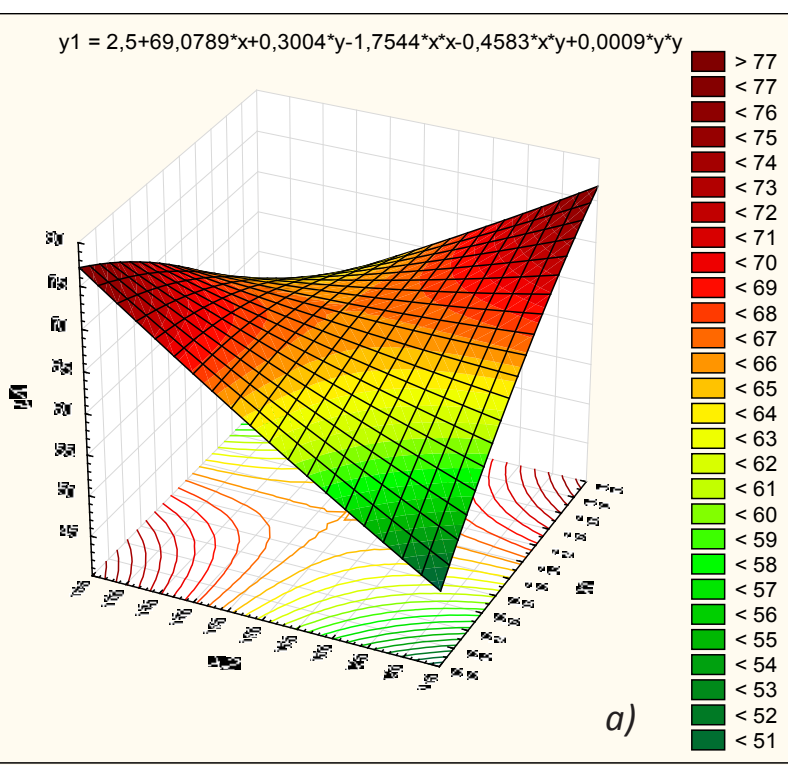

$y 5=39,9+3,5877^{*} x-0,2921^{*} y-0,7456^{*} x^{*} x-0,0167^{*} x^{*} y+0,0008^{*} y^{*} y$

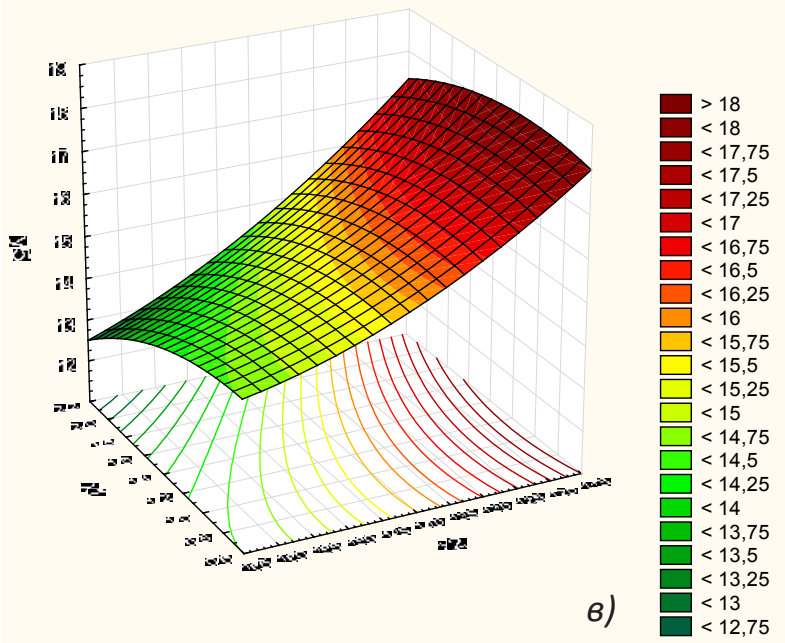

$D=39,9+3,59 \cdot x_{1}-0,29 \cdot x_{2}-0,75 \cdot x_{1}^{2}+0,000483$ $\cdot x_{2}^{2}-0,017 \cdot x_{1} \cdot x_{2}$

где Т - температура гранул, ${ }^{\circ} \mathrm{C} ; \mathrm{Q}$ - производительность гранулятора, кг/ч; $D$ - доза воздействия, Вт'с/г.

Анализ представленных выше уравнений позволил выявить режимы работы гранулятора, которые обеспечивают минимальные удельные энергетические затраты на процесс и максимальное снижение микробиологической обсемененности гранул. Многокритериальная оценка дала возможность выявить эффективные режимы гранулирования фуражной пшеницы: длина волны - 12,24 см; удельная мощность СВЧ генератора - 1,4...2 Вт/г; продолжительность воздействия ЭМПСВЧ на сырье массой 0,8...1 кг в резонаторной камере - $10 . .12$ с; плотность гранул - 1300...1500 кг/м³, производительность

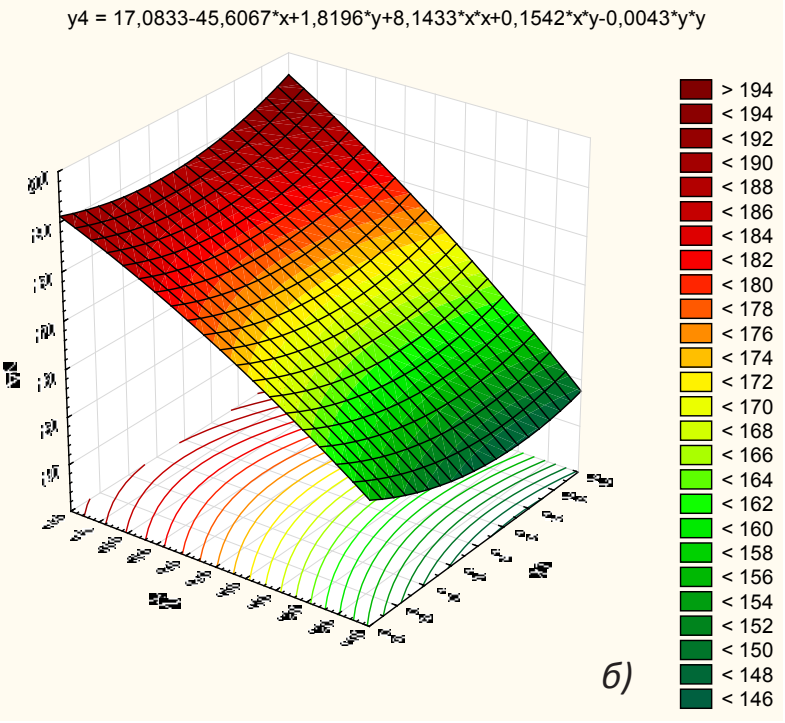

Рис. 3 - Поверхность отклика и двумерные сечения в изолиниях трехфакторных моделей: а) изменения температуры гранул из фруражной пшеницы с воздействием ЭМПСВ4; б) изменения производительности гранулятора с фуражной пшеницей; в) изменения дозы воздействия ЭМПСВЧ на гранулы из фруражной пшеницы

гранулятора - 182...194 кг/ч; температура гранул - 68...77 ${ }^{\circ} \mathrm{C}$.

\section{Выводы}

1. Разработанный гранулятор с цилиндрическим резонатором-матрицей обладает высокой производительностью, а также возможностью смены матриц с разными диаметрами отверстий при гранулировании измельченных зерновых отходов и отходов животного происхождения в процессе циклического сжимающего механического воздействия на сырье в СВЧ поле.

2. При производительности гранулятора 182...194 кг/ч и удельной мощности СВЧ генератора 1,4...2 Вт/г продолжительность воздействия ЭМПСВЧ на сырье массой 0,8...1 кг в резонаторной камере должна составлять 10...12 с. Это обеспечивает минимальные удельные энергетические затраты 0,06 кВт.ч/кг.

3. Повышения прочности гранул можно достичь не путем добавления в их исходные компоненты связующих веществ, как принято в машинах такого типа, а за счет избирательного диэлектрического нагрева многокомпонентного сырья.

Гранулирование многокомпонентного сырья с исходным уровнем обсемененности до 3 
млн КОЕ/г при воздействии ЭМПСВЧ обеспечивает снижение бактериальной обсемененности гранул до предельно допустимого уровня 500 тыс. KOE/г при достижении их температуры $68 . .77^{\circ} \mathrm{C}$.

\section{Библиографический список}

1. Киселев, А.А. Влажное гранулирование углеводно-витаминно-минеральной добавки на прессе с кольцевой матрицей / А.А. Киселев; под общ. ред. А.В. Туголукова // Перспективы развития науки и образования. Материалы III международной научно-практической конференции. - М., 2016 - С. 136 - 139.

2. Ковриков, И.Т. Математическая модель напряженного состояния растительного материала в цилиндрических фильерах матрицы пресс-гранулятора / И.Т. Ковриков, А.С. Кириленко // Фундаментальные и прикладные проблемы техники и технологии. - 2013. - № 2 (298). - С. 25 - 34.

3. Маврин, О. Оптимальное решение: гранулирование и термообработка за 240 секунд / О.Маврин // Комбикорма. - 2009. - № 1. - С. 33 - 35.

4. Особенности выбора гранулирующего оборудования многокомпонентных полидисперсных шихт, с вторичными материальными ресурсами на основе системного анализа / Д.А. Макаренков, В.И. Назаров, А.М. Гонопольский, Я.А. Трефилова // Вестник МГОУ. Серия «Естественные науки». - 2013. - № 1. - С. 49 - 64.

5. Процессы и аппараты пищевых производств. Книга 1 / А.Н. Остриков, Ю.В. Красовицкий, А.А. Шевцов [и др.]; под. ред. А.Н. Острикова. - СПб.: ГИОРД, 2007. - 704 с.

6. Фишер, Л.А. Возможности совершенствования производства комбикормов / Л.А. Фишер // Хранение и переработка сельхозсырья. - 2007. - № 6. - С. 79 - 81.

7. Афанасьев, В.А. Разработка технологии влажного прессования углеводно-витаминноминеральных добавок с повышением содер- жания мелассы / В.А. Афанасьев, А.А. Киселев // Вестник Воронежского государственного университета инженерных технологий. - 2015. - № 1 (63). - С.70 - 73.

8. Афанасьев, В.А. Проектирование, конструирование и разработка современного оборудования для комбикормовых предприятий / В.А. Афанасьев, О.В. Денисов, А.А. Киселев // Инновационное развитие техники пищевых технологий. Материалы международной научнотехнической конференции. - Воронеж, 2015. - С. $220-224$.

9. Булатов, Илья Анатольевич. Разработка процесса прессового гранулирования мелкодисперсных сред на примере минеральных порошков и древесных отходов: автореф. ...канд. технических наук: 05.17.08, 05.02.13 / И.А. Булатов. - М., 2012. - 25 с.

10. Пат. № 2629159 Российская Федерация, МПК А 23 N17/00. Сверхвысокочастотная установка с тороидальным резонатором и с ячеистым ротором для термообработки сырья / А.А. Белов, Г.В. Жданкин, Г.В. Новикова, О.В. Михайлова; патентообладатель НГСХА. - № 2016133524; заявл.15.08.2016; опубл.24.08.2017. Бюл. № 24. - 10 с.

11. Анализ разработанных сверхвысокочастотных установок для термообработки сырья / Г.В. Новикова, Г.В. Жданкин, О.В. Михайлова, А.А. Белов // Вестник Казанского государственного аграрного университета. - 2016. - № 4 (42). - С. 89 - 93.

12. Жданкин, Г.В. Разработка сверхвысокочастотной установки для термообработки непищевых боенских отходов / Г.В. Жданкин, Г.В. Новикова // Пермский аграрный Вестник. 2017. - № 4 (20). - С. 54 - 64.

13. Шамин, Е.А. Разработка сверхвысокочастотной установки с цилиндрическими резонаторами для сушки пушно-мехового сырья в непрерывном режиме // Е.А. Шамин, Б.Г. Зиганшин, Г.В. Новикова // Вестник НгИЭИ. - 2017. - № 9 (76). - С. 57 - 64.

\title{
ANALYSIS OF WORKING CHAMBERS WHICH PROVIDE THERMAL TREATMENT AND WASTE GRANULATION OF AGRICULTURAL RAW MATERIALS
}

\author{
Krainov Yu.E. ${ }^{1}$, Mikhailova O.V. ${ }^{1}$, Kirillov N. K. ${ }^{2}$ \\ ${ }^{1}$ SBEI HE Nizhny Novgorod University of Engineering and Economics \\ 606340. Nizhny Novgorod region., Knyaginino v., Oktyabrskaya st., 22. E-mail: krainov24@mail.ru \\ ${ }^{2}$ FSBEI HE Chuvash State Agricultural Academy, \\ 428003, Cheboksary, K-Marx st., 29.
}

Keywords: superhigh-frequency generator, resonator, granulator, matrix, raw material waste, regression models, effective regimes.

The aim of the work is to design an installation for granulating non-food wastes of animal and vegetable origin with the influence of an ultrahigh-frequency 
electromagnetic field on them. The research tasks included elaboration of a microwave installation with a cavity resonator which provides high electric field strength and continuous process of material granulation; substantiation of technological parameters of the granulator, taking into account the main criteria of technological process. The research was based on the theory of dielectric heating and the theory of formation of granules from multicomponent materials. The results of the experimental studies were processed with application of mathematical statistics and regression analysis, applying the theory of active planning of a multifactor experiment. An installation was devised that ensures granulation of raw materials in a continuous mode under the influence of EMFUHF. Its description and design analysis of the cavity resonator are given, taking into account the requirements for microwave installations intended for use on farms. The main requirements include the possibility of providing: radio-tightness of microwave equipment in a continuous mode of operation; high-temperature granulation at high electric field strength; variations of the installation capacity with low-power magnetrons, cooled with air. Analysis of the developed installation with a cylindrical resonator-matrix showed that the following modes of granulation of combined mixture are effective: wave length - $12.24 \mathrm{~cm}$; the specific power of the microwave generator is 1 ... $1.4 \mathrm{~W} / \mathrm{g}$; duration of EMFUHF exposure on raw materials weighing 0.8 ... $1 \mathrm{~kg}$ in the resonator chamber - 10 ... $12 \mathrm{~s}$; The density of granules is $1300 \ldots 1500 \mathrm{~kg} / \mathrm{m}^{3}$.

\section{Bibliography}

1. Kiselev, A.A. Wet granulation of a carbohydrate-vitamin-mineral supplement on a press with a ring matrix / A.A. Kiselev; eited by. A.V. Tugolukova // Prospects of science and education development. Materials of the III International Scientific and Practical Conference. - M., 2016 - P. 136 - 139.

2. Kovrikov, I.T. A mathematical model of stress state of plant material in matrix cylindrical spinnerets of a press granulator / I.T. Kovrikov, A.S. Kirilenko // Fundamental and applied problems of engineering and technology. - 2013. - No. 2 (298). - P. 25 - 34.

3. Mavrin, O. Suitable solution: granulation and heat treatment for 240 seconds / O.Mavrin // Mixed feeds. - 2009. - No. 1. - P. 33 - 35.

4. Features of granulating equipment for multicomponent polydisperse charges, with secondary material resources on the basis of system analysis / D.A. Makarenkov, V.I. Nazarov, A.M. Gonopolsky, Ya.A. Trefilova // Vestnik of Moscow State regional University. Series of "Natural Sciences". - 2013. - No. 1. - P. $49-64$.

5. Processes and devices of food production. Book 1 / A.N. Ostrikov, Yu.V. Krasovitsky, A.A. Shevtsov [et alt.]; edited by A.N. Ostrikov. - SPb .: GIORD, 2007. $-704 p$.

6. Fisher, L.A. Opportunities to improve the production of mixed feeds / L.A. Fisher // Storage and processing of agricultural raw materials. - 2007. - No. 6. - P. $79-81$.

7. Afanasiev, V.A. Development of the technology of wet pressing of carbohydrate-vitamin-mineral supplements with increased molasses content / V.A. Afanasiev, A.A. Kiselev //Vestnik of Voronezh State University of Engineering Technologies. - 2015. - No. 1 (63). - P.70 - 73.

8. Afanasiev, V.A. Design, construction and development of modern equipment for feed feed-milling establishment / V.A. Afanasiev, O.V. Denisov, A.A. Kiselev // Innovative development of technology of food technologies. Materials of the international scientific and technical conference. - Voronezh, 2015. - P. $220-224$

9. Bulatov, Iliya Anatolievich. Development of pressing granulation process of finely dispersed media on the example of mineral powders and wood waste: the authoris abstract of Caniate of Technical Sciences: 05.17.08, 05.02.13 / I.A. Bulatov. - M., 2012. - 25 p.

10. Pat. No. 2629159 Russian Federation, IPC A 23 N17/ 00. Ultrahigh-frequency installation with a toroidal resonator and with a cellular rotor for heat treatment of raw materials / A.A. Belov, G.V. Zhdankin, G.V. Novikova, O.V. Mikhailova; patent owner of Nizhniy Novgorod State Agricultural Academy. - No. 2016133524; appl 15.08.2016; published 24.08.2017. Bul. № 24. - 10 p.

11. Analysis of developed ultrahigh-frequency plants for heat treatment of raw materials / G.V. Novikova, G.V. Zhdankin, O.V. Mikhailova, A.A. Belov // Vestnik of Kazan State Agrarian University. - 2016. - No. 4 (42). - P. 89 - 93.

12. Zhdankin, G.V. Development of a microwave plant for heat treatment of non-food slaughter wastes / G.V. Zhdankin, G.V. Novikova // Perm Agrarian vestnik. - 2017. - No. 4 (20). - P. 54 - 64.

13. Shamin, E.A. Development of an ultrahigh-frequency installation with cylindrical resonators for drying fur raw materials in a continuous mode // E.A. Shamin, B.G. Ziganshin, G.V. Novikova // Vestnik of Nizhny Novgorod University of Engineering and Economics. - 2017. - No. 9 (76). - P. 57 - 64. 